\title{
Clinical Characteristics of Coronavirus Disease 2019 in Dr. Agoesdjam Regional Public Hospital, Ketapang, West Kalimantan, Indonesia
}

\author{
Herick Alvenus Willimi), Cristianto'), Yohana Roy Ito Br Sihombing1), \\ Eva Lydia Munthe'), Widi Mujono3), Enny4) \\ ${ }^{1)}$ General Practitioner, Dr. Agoesdjam Regional Public Hospital, \\ Ketapang Regency, West Kalimantan \\ 2)Department of Pulmonology and Respiratory Medicine, Dr. Agoesdjam Regional \\ Public Hospital, Ketapang Regency, West Kalimantan \\ 3)Department of Radiology, Dr. Agoesdjam Regional Public Hospital, \\ Ketapang Regency, West Kalimantan \\ 4)Department of Clinical Pathology, Dr. Agoesdjam Regional Public Hospital, \\ Ketapang Regency, West Kalimantan
}

\section{ABSTRACT}

Background: Coronavirus disease 2019 (COVID-19) is a new pandemic caused by SARS-CoV-2 infection. COVID-19 has spread to almost all countries with increasing cases, including Indonesia. Data on the clinical characteristics of COVID-19 in Indonesia is still limited. This study aimed to determine the clinical characteristics of COVID-19.

Subjects and Method: This study was a descriptive study with a retrospective design conducted in Dr. Agoesdjam Regional Public Hospital. The data were obtained from the medical records of all patients with confirmed COVID-19 from April 1 to July 31, 2020. There were 50 patients as the sample of the study. The data collected were demographics, exposure history, smoking status, comorbidities, clinical symptoms, outcomes, drug therapy, laboratory, chest X-ray, and electrocardiography (ECG). This study used descriptive statistics.

Results: The patients on average aged 34.8 years $($ Mean $=34.8 ; \mathrm{SD}=14.0)$. Patients were dominated by the $30-39$ years age group (28\%) and men (56\%). More than a third of patients (36\%) were health workers. Most of the cases were local transmission (78\%). Almost half of the patients (48\%) were smokers. The most common comorbid was hypertension (12\%). The dominant clinical symptoms were cough (34\%), dyspnea (14\%), and fever (10\%). More than half of the patients (58\%) were asymptomatic. The mortality rate was $2 \%$. All patients received supportive therapy. Azithromycin was the most potential drug given (30\%). Abnormal laboratory findings included leukocytosis (18\%), neutrophilia (20\%), lymphopenia (28\%), elevated erythrocyte sedimentation rate $(32 \%)$, alanine aminotransferase (36\%), and aspartate aminotransferase (18\%). Abnormal chest X-ray was found in $10 \%$ of patients. Among the 22 patients who were examined on the ECG, the abnormal figures were found in $40.9 \%$ of patients with non-specific findings.

Conclusion: The COVID-19 patients in this study are dominated by young adults and men. Asymptomatic and mild symptoms are more common. The symptoms that are often complained of are coughing, dyspnea, and fever. The common laboratory abnormalities were leucocytosis, neutrophilia, lymphopenia, elevated erythrocyte sedimentation rate, and elevated liver enzymes. The most common chest X-ray abnormality is consolidation. During the COVID-19 pandemic, prevention and control are the main priorities. In addition, the level of public awareness must be raised.

Keywords: COVID-19, SARS-CoV-2, clinical symptoms, electrocardiography

\section{Correspondence:}

Herick Alvenus Willim. Dr. Agoesdjam Regional Public Hospital, Ketapang Regency, West Kalimantan. Email: herick_alvenus@yahoo.co.id. Mobile: +6282252188675 . 
Willim et al./ Clinical Characteristics of Coronavirus Disease 2019

Cite this as:

Willim HA, Cristianto, Sihombing YRB, Munthe EL, Mujono W, Enny (2020). Clinical Characteristics of Coronavirus Disease 2019 in Dr. Agoesdjam Regional Public Hospital, Ketapang, West Kalimantan, Indonesia. J Epidemiol Public Health. 05(03): 293-308. https://doi.org/10.26911/jepublichealth.2020.05.03.04.

\section{BACKGROUND}

Coronavirus disease 2019 (COVID-19) is a new disease caused by infection with Severe Acute Respiratory Syndrome Coronavirus-2 (SARS-CoV-2). It is an enveloped ribonucleic acid (RNA) virus, a new $\beta$-coronavirus type previously known as the 2019 novel coronavirus (2019-nCoV). The first COVID-19 case was reported at the end of December 2019 in Wuhan, Hubei Province, China (Jin et al., 2020). Thenceforth, COVID-19 has spread rapidly across the globe. COVID-19 was defined by the World Health Organization (WHO) as a Public Health Emergency of International Concern (PHEIC) on January 30, 2020. In the end, it was declared a pandemic on March 11, 2020 (Hua et al., 2020).

SARS-CoV-2 is the seventh coronavirus that can infect humans. Four types of coronavirus such as 229E, OC43, NL63, and HKU1 are the common coronaviruses. They can cause mild symptoms such as a common cold. The three other coronaviruses, namely SARS-CoV (discovered in 2002), MERS-CoV (discovered in 2012), and SARS-CoV-2 can cause severe respiratory infections (Zhu et al., 2020). Bats are suspected to be natural reservoirs and pangolins are intermediate hosts of SARSCoV-2. However, this still requires further investigation (Zheng et al., 2020).

SARS-CoV-2 transmission can directly occur through the respiratory droplets that appeared when speaking, sneezing, or coughing, and indirectly occur through contaminated objects or surfaces. This transmission can occur from asymptomatic or symptomatic patients (Dhand et al.,
2020). The incubation period for COVID-19 ranges from 2-14 days (5 days on average). Clinical symptoms vary from asymptomatic to symptomatic with common symptoms including fever, cough, odynophagia, dyspnea, headache, fatigue, malaise, and myalgia. Generally, COVID-19 patients have a mild degree of disease, but some patients such as patients with old age or having comorbidity can progress to pneumonia, acute respiratory distress syndrome, sepsis, shock, and multi-organ dysfunction syndrome (Singhal et al., 2020).

Nowadays, COVID-19 has spread in almost all countries with a growing number of cases, including in Indonesia. Based on the WHO data on September 3, 2020, the number of COVID-19 cases worldwide is 25,842,652 with 858,629 deaths, while the number of COVID-19 cases in Indonesia was 180,646 cases with 7,616 deaths. The mortality rate for COVID-19 in Indonesia was $4.2 \%$. This rate was the highest number in Southeast Asia (World Health Organization, 2020). The first COVID-19 case in Ketapang Regency on April 1, 2020, was 1 case. Based on the data on September 3, 2020, the number of COVID-19 cases in Ketapang Regency was 87 cases (West Kalimantan Health Office, 2020).

Studies on COVID-19 are still very minimal in Indonesia. There have been no previous studies regarding the clinical characteristics of COVID-19 in West Kalimantan, especially in Ketapang Regency. Therefore, this study was important to do in Dr. Agoesdjam Regional Public Hospital that was a COVID-19 referral hospital in Ketapang Regency. The results of this study 
were expected to help clinicians recognize the clinical characteristics of COVID-19 so that they could carry out early detection and proper management.

\section{SUBJECTS AND METHOD}

1. Study Design and the Participants

This study was a descriptive study with a retrospective design. The data were obtained from medical records with a total sampling technique on all patients confirmed with COVID-19 at Dr. Agoesdjam Regional Public Hospital, Ketapang Regency, West Kalimantan, since the first case on April 1, 2020, to July 31, 2020. The patients were positive for COVID-19 based on the evidence of SARS-CoV-2 detection on nasopharyngeal and oropharyngeal swabs by reverse transcription-polymerase chain reaction (RT- PCR) examination based on the guidelines of the Indonesia Ministry of Health. The results of the RT-PCR examination were obtained from the microbiology laboratory of the Tanjungpura University Hospital in Pontianak or the Center for Environmental Health and Disease Control Engineering (BBTKLPP) in Jakarta. The sample of this study was 50 patients.

\section{Data Collection}

The data collected included demographics, history of exposure, smoking status, comorbidities, clinical symptoms, outcomes, drug therapy, laboratory, chest X-ray, and electrocardiography (ECG). Based on the severity of the disease, COVID-19 was classified into asymptomatic, mild, moderate, and severe. It was asymptomatic if there were no clinical characteristics and symptoms, and a normal chest X-ray. It was mild degree if there were symptoms of acute upper respiratory tract infections (fever, cough, sore throat, sneezing, runny nose, myalgia, fatigue) or digestive symptoms (abdominal pain, nausea, vomiting, and diarrhea). It was a moderate degree if there was pneumonia without characteristics of hypoxemia. It was a severe degree if there was pneumonia with hypoxemia, acute respiratory distress syndrome, sepsis, shock, or multi-organ dysfunction syndrome. The patients were declared recovered if the RT-PCR examination was negative twice in a row and there were no clinical characteristics or symptoms.

\section{Statistic Analysis}

This study used descriptive statistics and the Statistical Package for Social Sciences (SPSS) program version 20 to analyze the data. The qualitative data were in the form of frequency and percentage. The quantitative data were in the form of mean, standard deviation if the distribution of the data was normal and median (minimummaximum) if the distribution of the data was not normal.

\section{Research Ethics}

This study has been declared passed the ethical review by the research ethics committee of Dr. Agoesdjam Regional Public Hospital with letter number: 05/KOMED/RSUD/2020. The patient informed consent was not required because the study was retrospective.

\section{RESULTS \\ 1. The demographic and clinical characteristics}

The mean age of the patients in this study was 34.80 years $(\mathrm{Mean}=34.8 ; \mathrm{SD}=14.0)$. The age group was dominated by patients aged 30-39 years by 14 patients (28\%). The sex was dominated by the males by 28 patients (56\%). A total of 18 patients (36\%) were health workers. There were 11 imported cases (22\%): 6 cases (12\%) came from the Islamic boarding school cluster in East Java, 4 cases (8\%) came from the cluster of worship place in Malaysia, and 1 case $(2 \%)$ came from a cluster of worship 
place in West Java. There were 39 cases of local transmission (78\%).

A total of 24 patients (48\%) were smokers. Hypertension was the most common comorbid, which was 6 patients (12\%), followed by 2 patients with diabetes (4\%). The cough was the most dominant clinical symptom found in 17 patients (34\%), followed by dyspnea in 7 patients (14\%), and fever in 5 patients (10\%). A total of 29 patients (58\%) had no symptoms (asymptomatic). Patients with mild, moderate, and severe disease degrees were 17 patients (34\%), 3 patients (6\%), and 1 patient (2\%) sequentially. A total of 49 patients (98\%) had recovered, while 1 patient (2\%) died. The demographic and clinical characteristics of the subjects of the study can be seen in Table 1.

\section{Drug therapy}

All patients received supportive therapy according to patient needs. There were several potential drug classes used for the management of COVID-19 patients, including antivirus (oseltamivir), antibiotic (azithromycin), and antimalarial (hydroxychloroquine). Azithromycin was the drug most often given, that was in 15 patients (30\%), followed by hydroxychloroquine in 7 patients (14\%), and oseltamivir in 5 patients (10\%). The characteristics of drug therapy in study subjects can be seen in Table 2.

\section{The characteristics of the laboratory}

Based on the laboratory data at admission, the leukocytes of 9 patients (18\%) increased with a median value by $8.1(4.8-16.7) \times 10^{3} /$ $\mu$ l. Neutrophils increased in 10 patients (20\%) and decreased in 7 patients (14\%). Lymphocytes increased in 5 patients (10\%) and decreased in 14 patients (28\%). Hemoglobin increased in 5 patients (10\%) and decreased in 3 patients (6\%). All patients had platelets in normal limits. The neutrophil-to-lymphocyte ratio (NLR) increased in 9 patients (18\%). The erythrocyte sedimentation rate increased to 16 patients (32\%). Alanine aminotransferase increased in 18 (36\%) and aspartate aminotransferase increased in 9 patients (18\%). The characteristics of the laboratory of the study subjects are in Table 3.

\section{The characteristics of the Chest $X$ - Ray}

A normal chest X-ray was found in 45 patients (90\%), while abnormal chest X-ray was found in 5 patients (10\%). Abnormal findings included consolidation in 4 patients (8\%), cardiomegaly in 2 patients (4\%), and cavities in 1 patient ( $2 \%$ ). The distribution of pulmonary abnormalities was found bilaterally in 3 patients (6\%) and unilateral in 1 patient (2\%). The characteristics of the chest X-ray of the study subjects can be seen in Table 4 and Figure 1.

(A) Chest X-ray of an asymptomatic a 20-year-old male patient was normal. (B) A chest X-ray of a 68-year-old male patient showed multifocal consolidation in both lungs, especially in the peripheral zone. (C) A chest X-ray of a 27-year-old male patient showed consolidation in the upper field of the right lung. (D) Chest X-ray of a 20-yearold female patient showed cardiomegaly with increased bronchovascular features. (E) Chest X-ray of a 38-year-old male patient with an active pulmonary tuberculosis coinfection showed cardiomegaly with multifocal consolidation in both lungs and cavity in the lower field of the right lung. (F) A chest X-ray of a 41-year-old male patient with a history of pulmonary tuberculosis showed inhomogeneous consolidation in both lungs, especially in the left perihilar accompanied by the deviation of the trachea and heart to the left. 
Willim et al./ Clinical Characteristics of Coronavirus Disease 2019

Table 1. The demographic and clinical characteristics $(N=50)$

\begin{tabular}{|c|c|c|}
\hline Characteristic & Mean & SD \\
\hline Age (years) & $\begin{array}{c}34.80 \\
\mathbf{N}\end{array}$ & $\begin{array}{c}14.00 \\
\%\end{array}$ \\
\hline \multicolumn{3}{|l|}{ Age group (years) } \\
\hline $0-9$ & 1 & 2 \\
\hline $10-19$ & 5 & 10 \\
\hline $20-29$ & 12 & 24 \\
\hline $30-39$ & 14 & 28 \\
\hline $40-49$ & 12 & 24 \\
\hline $50-59$ & 2 & 4 \\
\hline $60-69$ & 4 & 8 \\
\hline \multicolumn{3}{|l|}{ Sex } \\
\hline Male & 28 & 56 \\
\hline Female & 22 & 44 \\
\hline \multicolumn{3}{|l|}{ Occupation } \\
\hline Health worker & 18 & 36 \\
\hline Non-health worker & 32 & 64 \\
\hline Import cases & 11 & 22 \\
\hline East Java & 6 & 12 \\
\hline Malaysia & 4 & 8 \\
\hline West Java & 1 & 2 \\
\hline Local transmission & 39 & 78 \\
\hline \multicolumn{3}{|l|}{ Smoking Status } \\
\hline Smoker & 24 & 48 \\
\hline Non-smoker & 26 & 52 \\
\hline \multicolumn{3}{|l|}{ Comorbid } \\
\hline Hypertension & 6 & 12 \\
\hline Diabetes & 2 & 4 \\
\hline Chronic kidney disease & 1 & 2 \\
\hline HIV/AIDS & 1 & 2 \\
\hline Active pulmonary TB & 1 & 2 \\
\hline Active pulmonary TB & 1 & 2 \\
\hline \multicolumn{3}{|l|}{ Symptoms } \\
\hline Cough & 17 & 34 \\
\hline Dyspnea & 7 & 14 \\
\hline Fever & 5 & 10 \\
\hline Odynophagia & 3 & 6 \\
\hline Stomachache & 3 & 6 \\
\hline Anorexia & 3 & 6 \\
\hline Nausea/vomiting & 3 & 6 \\
\hline Fatigue & 2 & 4 \\
\hline Cold & 1 & 2 \\
\hline \multicolumn{3}{|l|}{ Severity classification } \\
\hline Asymptomatic & 29 & 58 \\
\hline Mild & 17 & 34 \\
\hline Moderate & 3 & 6 \\
\hline Severe & 1 & 2 \\
\hline \multicolumn{3}{|l|}{ Outcome } \\
\hline Recovered & 49 & 98 \\
\hline Died & 1 & 2 \\
\hline
\end{tabular}


Willim et al./ Clinical Characteristics of Coronavirus Disease 2019

Table 2. The characteristics of drug therapy $(\mathrm{N}=50)$

\begin{tabular}{cc}
\hline \multicolumn{1}{c}{ Drug Class } & N (\%) \\
\hline Antivirus & $5(10)$ \\
Oseltamivir & \\
Antibiotic & $15(30)$ \\
Azithromycin & $7(14)$ \\
Antimalaria & 7 Hydroxychloroquine \\
\hline
\end{tabular}

Table 3. The characteristics of the laboratory $(N=50)$

\begin{tabular}{|c|c|c|}
\hline Parameter & $\begin{array}{l}\text { Mean } \pm \text { SD, Median } \\
(\min -m a x), \text { or N (\%) }\end{array}$ & $\begin{array}{l}\text { Normal } \\
\text { Referral }\end{array}$ \\
\hline Leukosit (x 103/ $\mu$ l) & $8.1(4.8-16.7)$ & $3.6-11.0$ \\
\hline Increased & $9(18)$ & \\
\hline Decreased & $0(0)$ & \\
\hline Neutrophil (\%) & $62.0 \pm 11.6$ & $50-70$ \\
\hline Increased & $10(20)$ & \\
\hline Decreased & $7(14)$ & \\
\hline Lymphocyte (\%) & $29.0 \pm 9.9$ & $25-40$ \\
\hline Increased & $5(10)$ & \\
\hline Decreased & $14(28)$ & \\
\hline Hemoglobin (g/dL) & $14.3(10.1-17.7)$ & $11.7-15.8$ \\
\hline Increased & $5(10)$ & \\
\hline Decreased & $3(6)$ & \\
\hline 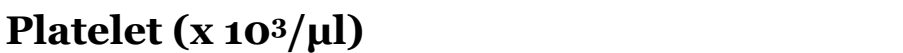 & $286(179-422)$ & $150-440$ \\
\hline Increased & o (o) & \\
\hline Decreased & $\mathrm{o}(0)$ & \\
\hline Neutrophil-to-lymphocyte ratio & $2.1(0.4-31)$ & $<3.1$ \\
\hline Increased & $9(18)$ & \\
\hline Erythrocyte sedimentation rate ( $\mathrm{mm} / \mathrm{hour}$ ) & $14.5(2-63)$ & $<20$ \\
\hline Increased & $16(32)$ & \\
\hline Alanine aminotransferase $(\mathbf{U} / \mathrm{L})$ & $29(10-141)$ & $<35$ \\
\hline Increased & $18(36)$ & \\
\hline Aspartate aminotransferase (U/L) & $26(11-71)$ & $<35$ \\
\hline Increased & $9(18)$ & \\
\hline
\end{tabular}

Table 4. The characteristics of the Chest $X-R a y(N=50)$

\begin{tabular}{lc}
\hline \multicolumn{2}{c}{ Findings } \\
\hline Normal N (\%) \\
Abnormal & $45(90)$ \\
Findings & $5(10)$ \\
Consolidation & \\
Cardiomegaly & $4(8 \%)$ \\
Cavity & $2(4 \%)$ \\
Distribution of pulmonary abnormalities & $1(2 \%)$ \\
Bilateral & \\
Unilateral & $3(6 \%)$ \\
\hline
\end{tabular}




\section{The characteristics of the electro- cardiography}

Among the 50 patients, 22 patients underwent an ECG examination. There were 9 patients (40.9\%) who had abnormal ECGs. All patients had sinus rhythm. A total of 19 patients (86.4) had normal frequency, 2 patients (9.1\%) had sinus tachycardia, and 1 patient (4.5\%) had sinus bradycardia. The right axis deviation was found in 2 patients
(9.1\%). All patients had normal PR intervals. The left atrial enlargement was found in 2 patients (9.1\%). The left ventricular hypertrophy was found in 1 patient (4.5\%). The right bundle branch block was found in 1 patient (4.5\%). T inversion was found in 2 patients (9.1\%). QTc prolongation was found in 1 patient (4.5\%). The characteristics of the ECG of study subjects can be seen in table 5 .

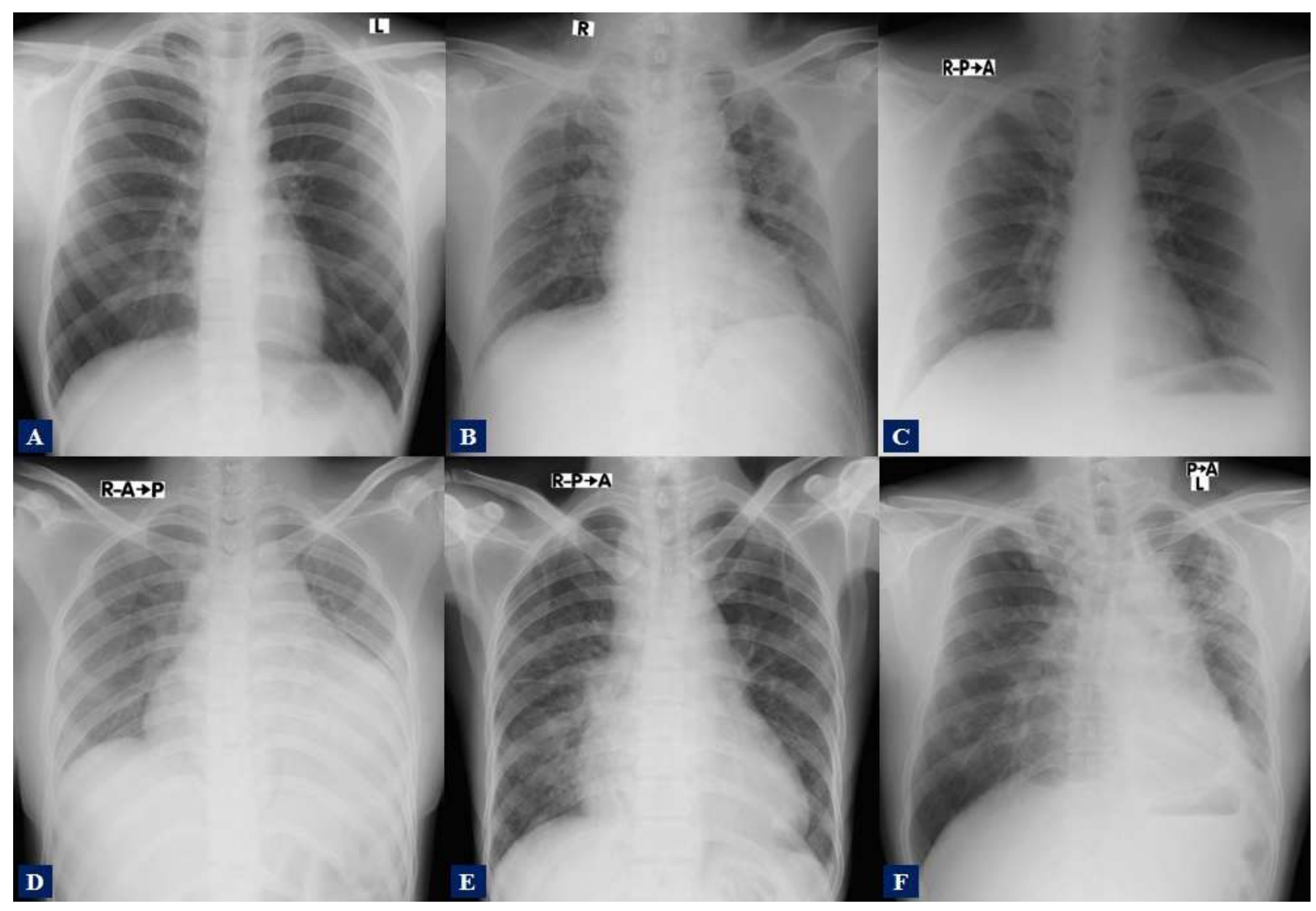

Figure 1. The chest $X$-ray findings of Patients with Confirmed COVID-19. 
Willim et al./ Clinical Characteristics of Coronavirus Disease 2019

Table 5. The characteristics of the electrocardiography $(\mathrm{N}=22)$

\begin{tabular}{|c|c|}
\hline Parameter & N (\%) \\
\hline Normal & $13(59.1)$ \\
\hline Abnormal & $9(40.9)$ \\
\hline \multicolumn{2}{|l|}{ Rhythm } \\
\hline Sine & $22(100)$ \\
\hline Non-sine & $\mathrm{o}(\mathrm{O})$ \\
\hline \multicolumn{2}{|l|}{ Frequency } \\
\hline Normal & $19(86.4)$ \\
\hline Tachycardia & $2(9.1)$ \\
\hline Bradycardia & $1(4.5)$ \\
\hline \multicolumn{2}{|l|}{ Axis } \\
\hline Normal & $20(90.9)$ \\
\hline Right axis deviation & $2(9.1)$ \\
\hline Left axis deviation & $o(0)$ \\
\hline \multicolumn{2}{|l|}{ PR Interval } \\
\hline Normal & $22(100)$ \\
\hline Lengthwise & o (o) \\
\hline \multicolumn{2}{|l|}{ Atrial enlargement } \\
\hline Left atrial enlargement & $2(9.1)$ \\
\hline Right atrial enlargement & o (o) \\
\hline \multicolumn{2}{|l|}{ Ventricular hypertrophy } \\
\hline Left ventricular hypertrophy & $1(4.5)$ \\
\hline Right ventricular hypertrophy & $\mathrm{o}(\mathrm{o})$ \\
\hline \multicolumn{2}{|l|}{ Bundle branch block } \\
\hline Right bundle branch block & $1(4.5)$ \\
\hline Left bundle branch block & $\mathrm{o}(\mathrm{o})$ \\
\hline \multicolumn{2}{|l|}{ Ischemic } \\
\hline T inversion & $2(9.1)$ \\
\hline ST elevation & $\mathrm{o}(\mathrm{o})$ \\
\hline ST depression & o (o) \\
\hline \multicolumn{2}{|l|}{ QTe Interval } \\
\hline Normal & $21(95 \cdot 5)$ \\
\hline Lengthwise & $1(4.5)$ \\
\hline
\end{tabular}

\section{DISCUSSION}

1. The demographic and clinical findings on COVID-19

Most of the patients in this study were relatively young with a mean age of 34.8 years and the most common age was in the 30-39-year age group (28\%). This finding is in line with a study conducted by Karyono et al. (2020) that the majority of COVID-19 cases in Indonesia occurred in the $31-45^{-}$ year age group (29.3\%). Young adults were a group that played a significant role in the COVID-19 transmission because they were more often involved in social activities, work, and tourism (Liao et al., 2020). More than half of the patients (56\%) in this study were men. The literature reported that men were more susceptible to contracting COVID-19 and had higher morbidity and mortality than women. Expression of the 
SARS-CoV-2 receptor, namely angiotensinconverting enzyme 2 (ACE2), was higher in men. The cause was unknown, but it might be associated with a higher number of smokers in men (Bwire et al., 2020).

More than a third of patients (36\%) were health workers. Health workers are at the front line of handling COVID-19 so that they are a group that is vulnerable to contracting COVID-19. Several factors caused the high number of infected health workers, such as lack of access to adequate personal protective equipment and lack of training or supervision regarding the prevention of COVID-19 (Itodo et al., 2020). The COVID19 cases in this study were dominated by local transmission cases. Most of the imported cases came from East Java (12\%). East Java is one of the epicenters of COVID-19 in Indonesia. The Indonesian government has made efforts to reduce the number of COVID-19 transmission by implementing large-scale social restrictions (PSBB). Half of the patients (48\%) in this study were smokers. Smokers had a higher expression of ACE2 in the lungs than nonsmokers, so they were more susceptible to have COVID-19 and could manifest more severely (Cai et al., 2020).

Most of the comorbids in this study were hypertension (12\%). This finding is in line with a study conducted by Cao et al. (2020) on 80 COVID-19 patients that hypertension was the most common comorbid (25.0\%), followed by cardiovascular disease (12.5\%), diabetes (7.5\%), and chronic obstructive pulmonary disease (6.3\%). Based on a study on 1099 COVID19 patients in China, $38.7 \%$ of patients who had comorbids had severe COVID-19 (Guan et al., 2020). Patients with comorbidities had higher ACE2 expression than patients without comorbidities so that they had a higher risk of having severe symptoms if they were infected with COVID-19 (Pinto et al., 2020). The researchers found 1 patient with active pulmonary tuberculosis (TB) coinfection and 1 patient with a history of pulmonary TB scars. Pulmonary TB is still a major public health problem in Indonesia so that co-infection can potentially occur. Liu et al. (2020) reported that patients with active pulmonary TB were more susceptible to infection with COVID-19. In addition, they were at risk of having more severe symptoms. Further investigation regarding the relationship between active pulmonary TB or former pulmonary TB and COVID-19 still need to be carried out.

Cough (34\%), dyspnea (14\%), and fever (10\%) were the dominant symptoms found in this study. Based on a study conducted by Colaneri et al. (2020) on 44 COVID-19 patients, the dominant symptoms were fever (90.9\%), cough (34.1\%), and dyspnea (22.7\%). More than half of the patients (58\%) in this study were asymptomatic. Asymptomatic cases of COVID-19 need attention because they are often not realized. Recent evidence showed that asymptomatic COVID-19 patients could transmit the virus to other patients and the level of infectivity was similar to symptomatic patients (Zhao et al., 2020). All COVID-19 patients, both symptomatic and asymptomatic, need to carry out contact tracing to break the chain of transmission.

Among the 50 patients in this study, 49 patients had recovered and 1 person died. As a result, the mortality rate in this study was $2 \%$. The patient who died in this study was a female patient aged 20 years without comorbid, came with severe symptoms, died on the 4 th day of treatment due to complications of respiratory failure and multiorgan failure. According to the literature, death in COVID-19 is generally caused by complications such as septic shock, pulmonary embolism, acute respiratory distress syndrome, respiratory failure, and 
multiorgan failure. This complication was more common in patients with comorbidities such as old age, hypertension, diabetes, cardiovascular disease, chronic obstructive pulmonary disease, and chronic kidney disease (Elezkurtaj et al., 2020).

\section{The drug therapy in COVID-19}

All patients in the study received supportive therapy. Until now, there is no specific drug therapy for COVID-19. Azithromycin is a potential drug most widely used in patients in this study, both monotherapy or in combination with other drugs such as hydroxychloroquine or oseltamivir. Azithromycin is a macrolide antibiotic that has an antiviral effect in the Zika virus, Ebola, and rhinovirus (Sultana et al., 2020). Chloroquine and hydroxychloroquine are antimalarial drugs that have antiviral effect in the human immunodeficiency virus (Rosa et al., 2020). Nowadays, many studies examining the effectiveness of azithromycin and hydroxychloroquine in COVID-19.

Azithromycin and hydroxychloroquine were reported to have immunomodulatory effects. It could reduce viral load thus having a benefit in COVID-19 patients (Gautret et al., 2020). Ashad et al. (2020) stated that giving hydroxychloroquine monotherapy or in combination with azithromycin is associated with reduced mortality in COVID-19. However, further prospective study still needs to be conducted. Oseltamivir is an antiviral drug for influenza that could be a potential drug for COVID-19. However, its efficacy could not be concluded because several clinical trials are still ongoing (Wu et al., 2020). Lopinavir/ritonavir, favipiravir, and remdesivir were other potential antivirals that were currently being widely studied (Yavuz et al., 2020).

3. The laboratory findings on COVID19
The hematologic abnormalities that were found in this study were leukocytosis (18\%), neutrophilia (20\%), and lymphopenia (28\%). This finding is in line with a study conducted by Hafiz et al. (2020) of 30 COVID-19 patients at a secondary referral hospital in Jakarta, that leukocytosis was found in $16.7 \%$ of patients, neutrophilia was found in $76.9 \%$, and lymphopenia was found in $70 \%$ of patients. The literature has linked leukocytosis, neutrophilia, and lymphopenia with severe COVID-19 (Huang et al., 2020). Neutrophilia was an expression of the hyperinflammatory condition and cytokine storm in COVID-19. Neutrophilia could also indicate bacterial co-infection. Lymphopenia could be caused by lymphocyte apoptosis induced by a cytokine storm (Violetis et al., 2020). Increased and decreased hemoglobin were found in $10 \%$ and $6 \%$ of patients, respectively. No literature explains exactly how COVID-19 affects hemoglobin. Lippi et al. (2020) stated that decreased hemoglobin could occur in severe COVID-19 and it was associated with poor clinical outcomes. An increase in NLR was found in almost one-fifth of patients (18\%). NLR was an inflammatory marker that had prognostic value in COVID-19. NLR could be used as a screening parameter to identify high-risk patients. NLR $\geq 3.13$ was a predictor of severe disease in COVID-19 (Liu et al., 2020).

Elevated erythrocyte sedimentation rate was found in almost one-third of patients (32\%). This finding is in line with the meta-analysis conducted by RodriguezMorales et al. (2020) that the erythrocyte sedimentation rate of $41.8 \%$ of 157 patients increased. Recent studies have shown that increased inflammatory markers such as erythrocyte sedimentation rate, C-reactive protein, procalcitonin, serum ferritin, and interleukin-6 were associated with the severity of COVID-19. The inflammatory 
response induced by the rapid replication of SARS-CoV-2 and cellular damage could lead to the recruitment of macrophages and induced the release of large amounts of cytokines and chemokines. These cytokines and chemokines would further activate the immune response and could cause systemic hyperinflammation and cytokine storms that worsening the disease conditions (Zeng et al., 2020).

Alanine aminotransferase (ALT) elevated in more than one-third of patients (36\%), while aspartate aminotransferase (AST) in almost one-fifth of patients (18\%). Both ALT and AST were markers of liver injury. These findings are in line with a study conducted by Cai et al. (2020) of 417 COVID-19 patients who found an increase in ALT and AST in $23.4 \%$ and $14.8 \%$ of patients, respectively. The mechanism of liver injury in COVID-19 was not fully understood. It was suspected that SARSCoV-2 could bind directly to ACE2 in cholangiocytes and cause liver injury. Excessive immune response and cytokine storms were might contribute to liver injury. The severity of the disease, the presence of liver disease, and old age increased the risk of liver injury (Alqahtani et al., 2020)

\section{The chest X-ray findings in COVID- 19}

Abnormal chest X-ray in this study was only found in 5 of 50 patients with the most common abnormality was consolidation (8\%). This finding is not as much as the study conducted by Wong et al. (2020) that abnormal chest x-ray in 51 out of 64 COVID-19 patients with the most common abnormality was in the form of consolidation (47\%). This difference might occur due to a large number of asymptomatic COVID-19 patients and mild symptoms in our study. As a result, most of them had normal chest X-rays. Computed tomo- graphy (CT scan) facilities were not yet available at Dr. Agoesdjam Regional Public Health. Therefore, a chest X-ray examination was used as a radiological modality in detecting COVID-19.

In this study, the finding of multifocal consolidation in both lungs especially in the peripheral zone (Figure 1B) was the most suggestive of COVID-19. According to the literature, the chest radiograph that can be found in COVID-19 includes consolidation and/or multifocal ground-glass opacity with a distribution that is often bilateral, peripheral, and predominant in the lower zone (Cleverley et al., 2020). The cardiomegaly found (Figures $1 \mathrm{D}$ and $1 \mathrm{E}$ ) were not specific for COVID-19. It could occur due to the intracardiac. In rare cases occurred, cardiomegaly could be caused by complications of SARS-CoV-2 myocarditis ( $\mathrm{Hu}$ et al., 2020). The cavity was rarely found in COVID-19. It was non-specific and could be caused by bacterial superinfection (Jajodia et al., 2020). In this study, the cavity in 1 patient (Figure 1E) occurred due to pulmonary TB coinfection.

Chest X-ray had a lower sensitivity than a chest CT scan. Cozzi et al. (2020) stated that a chest X-ray had a sensitivity of 67.1\% in detecting COVID-19. Therefore, normal chest X-ray findings could not rule out COVID-19. A chest CT scan is an important modality for early diagnosis of COVID-19 because it has a high sensitivity of $92 \%$ (Xu et al., 2020). Sometimes, the initial negative to positive RT-PCR examination result interval could reach 4-8 days, so that the evaluation with chest imaging was very important to help establish an early diagnosis of patients with suspected COVID-19 (Akcay et al., 2020). In areas with limited facilities, chest X-ray could still be the first-line imaging modality in patients with suspected COVID-19 because 
it was cost-effective and often available (Sarkodie et al., 2020).

\section{The electrocardiographic findings in COVID-19}

In this study, not all patients had an ECG examination. There were only 22 patients underwent ECG examination for indications such as moderate-severe symptoms, old age, had cardiovascular comorbidities, ruled out clinical suspicion of myocardial ischemia, or assessment of the QTc interval in patients receiving azithromycin or hydroxychloroquine. Some of the abnormal ECG findings in this study included sinus tachycardia (9.1\%), sinus bradycardia (4.5\%), right axis deviation (9.1\%), left atrial enlargement (9.1\%), left ventricular enlargement (4.5\%), right bundle branch block (4.5\%), T inversion (9.1\%), and QTc interval lengthening (4.5\%). The results of this study were slightly different from the study conducted by Angeli et al. (2020) regarding ECG in 50 patients with COVID19 , where there was atrial fibrillation in $6 \%$ of patients, tachycardia-bradycardia syndrome in $2 \%$ of patients, ST elevation associated with acute pericarditis in $12 \%$ of patients, left ventricular hypertrophy in $33 \%$ of patients, and right bundle branch block in $4 \%$ of patients.

Cardiac involvement in COVID-19 patients could be indicated by changes in the ECG. Sinus tachycardia was the most common ECG manifestation in COVID-19, which could be caused by the body's physiological response to fever, hypovolume, hypoxia, or hypoperfusion (Sia et al., 2020). Temporary sinus bradycardia could occur to COVID-19. Inflammatory cytokines released by an excessive immune response could interfere with the function of the sinoatrial nodes and contribute to bradycardia. Sinus bradycardia could be a warning sign of cytokine storms and it was associated with poor output, especially in patients with a history of cardiovascular disease (Amaratunga et al., 2020).

The right axis deviation found in this study was non-specific, it can be a normal variant. In rare cases, finding on a right axis deviation with sinus tachycardia, right ventricular strain pattern, and $\mathrm{S}_{1} \mathrm{Q} 3 \mathrm{~T} 3$ pattern should be suspected that there was a pulmonary embolism. It needs to be a concern, especially in severe COVID-19 due to the high incidence of hypercoagulation with an increased incidence of venous thromboembolism such as pulmonary embolism (Kho et al., 2020). Left atrial enlargement and left ventricular hypertrophy found in this study might occur due to underlying hypertension. McCullough et al. (2020) reported that COVID-19 patients with right bundle branch block and $\mathrm{T}$ inversion had an increased risk of mortality. The use of azithromycin, chloroquine, and hydroxychloroquine in COVID-19 patients has been associated with a risk of QTc prolongation due to the cardiotoxicity effects of these drugs. It might increase the risk of developing torsades de pointes (Chorin et al., 2020). QTc prolongation can also be caused by electrolyte disturbances, ischemia, and inflammation of the myocardium (Merino et al., 2020).

In conclusion, the COVID-19 patients in this study are dominated by young adults and males. Asymptomatic and mild symptoms are more common than moderate and severe symptoms. The most common symptoms are coughing, dyspnea, and fever. Common laboratory abnormalities are leukocytosis, neutrophilia, lymphopenia, elevated erythrocyte sedimentation rate, and increased liver enzymes. The most common chest $\mathrm{X}$-ray abnormality is consolidation. ECG findings are non-specific. However, it is important to detect cardiac involvement. During the COVID-19 pandemic, prevention and control are the top 
priorities. The level of public awareness of COVID-19 needs to be increased to prevent continued transmission. The principle of social distancing, using masks when leaving the house or sick, and washing hands regularly with soap and water must be obeyed by the whole community

\section{AUTHOR CONTRIBUTION}

All writers actively contributed to write this script. Herick Alvenus Willim, Cristianto, and YohanaRoy Ito Br Sihombing contributed to the study concepts, the data collection, the data analysis, the literature analysis, and the scriptwriting. Eva Lydia Munthe contributed to the patient management, the supervision of the data collection, and the revision of the manuscripts. Widi Mujono contributed to the interpretation of the chest photo and the revision of the manuscript. Enny contributed to the interpretation of the laboratory results and the revision of the manuscript. All authors have approved the final manuscript.

\section{CONFLICT OF INTEREST}

The authors declare that there is no conflict of interest in the publication of this article.

\section{FUNDING AND SPONSORSHIP}

The author does not receive financial support in the publication of this article.

\section{ACKNOWLEDGEMENT}

The author would like to thank Dr. Agoesdjam Regional Public Hospital for supporting and giving permission to collect medical record data for COVID-19 patients for this study.

\section{REFERENCE}

Akcay S, Ozlu T, Yilmaz A (2020). Radiological approaches to COVID-19 pneumonia.Turk J Med Sci, 50(3): 604610. doi: 10.3906/sag-2004-16o.
Alqahtani SA, Schattenberg JM (2020). Liver injury in COVID-19: the current evidence. United European Gastroenterol J, 8(5): 509-519. doi: 10.1177/2050640620924157.

Amaratunga EA, Corwin DS, Moran L, Snyder R (2020). Bradycardia in patients with COVID-19: a calm before the storm? Cureus, 12(6): e8599. doi: 10.7759/cureus.8599.

Angeli F, Spanevello A, Ponti RD, Visca D, Marazzato J, Palmiotto G, Feci D, et al. (2020). Electrocardiographic features of patients with COVID-19 pneumonia. Eur J Intern Med, 78: 101-106. doi: 10.1016/j.ejim.2020.06.015 .

Arshad S, Kilgore P, Chaudhry ZS, Jacobsen G, Wang DD, Huitsing K, Brar I, et al. (2020) Treatment with hydroxychloroquine, azithromycin, and combination in patients hospitalized with COVID-19.Int J Infect Dis, 97: 396403. doi: 10.1016/j.ijid.2020.06.099.

Bwire GM (2020). Coronavirus: why men are more vulnerable to Covid-19 than women? SN Compr Clin Med. doi: 10.1007/s42399-020-00341-w.

Cai G, Bosse Y, Xiao F, Kheradmand F, Amos CI (2020). Tobacco smoking increases the lung gene expression of ACE2, the receptor of SARS-CoV2.Am J Respir Crit Care Med, 201(12): 1557-1559. doi: 10.1164/rccm.202003-0693LE.

Cai Q, Huang D, Yu H, Zhu Z, Xia Z, Su Y, Li Z, et al. (2020).COVID-19: abnormal liver function tests.J Hepatol, 73(3): 566-574. doi: 10.1016/j.jhep.2020.04.006.

Cao Z, Li T, Liang L, Wang H, Wei F, Meng $S$, Cai M,et al. (2020). Clinical characteristics of coronavirus disease 2019 patients in Beijing, China.PLoS One, 15(6): e0234764. doi: 10.1371/jour- 
nal.pone.0234764.

Chorin E, Wadhwani L, Magnani S, Dai M, Shulman E, Nadeau-Routhier C, Knotts R, et al. (2020). QT interval prolongation and torsade de pointes in patients with COVID-19 treated with hydroxychloroquine/azithromycin. Heart Rhythm, 17(9):14251433. doi: 10.1016/j.hrthm.2020.05.014 .

Cleverley J, Piper J, Jones MM (2020). The role of chest radiography in confirming covid-19 pneumonia. BMJ, 370: m2426. doi: 10.1136/bmj.m2426.

Colaneri M, Sacchi P, Zuccaro V, Biscarini S, Sachs M, Roda S, Pieri TC, et al. (2020). Clinical characteristics of coronavirus disease (COVID-19) early findings from a teaching hospital in Pavia, North Italy, 21 to 28 February 2020.Euro Surveill, 25(16): 2000460. doi: 10.2807/1560-7917.ES.2020.25.16.2000460.

Cozzi D, Albanesi M, Cavigli E, Moroni C, Bindi A, Luvara S, Lucarini S, et al. (2020). Chest x-ray in new coronavirus disease 2019 (COVID-19) infection: findings and correlation with clinical outcome.Radiol Med. doi: 10.1007/s11547-020-01232-9.

Dhand R, Li J (2020).Coughs and sneezes: their role in transmission of respiratory viral infections, including SARSCoV-2.Am J Respir Crit Care Med, 202(5): 651-659. doi: 10.1164/rccm.202004-1263pp.

Dinas Kesehatan Kalimantan Barat (2020). Dashboard COVID-19 Kalbar. Available at: https://dinkes.kalbarprov.go.id/covid-19/ (Accessed 3 September 2020).

Elezkurtaj S, Greuel S, Ihlow J, Michaelis E, Bischoff P, Kunze CA, Sinn VB, et al. (2020). Causes of death and comorbidities in patients with COVID-19.
MedRxiv Preprint. doi: 10.1101/2020.06.15.20131540.

Gautret P, Lagier JC, Parola P, Hoang VT, Meddeb L, Mailhe M, Doudier B,et al. (2020). Hydroxychloroquine and azithromycin as a treatment of COVID19: results of an open-label non-randomized clinical trial. Int $\mathrm{J}$ Antimicrob Agents, 56(1):105949. doi: 10.1016/j.ijantimicag.2020.105949.

Guan W, Ni Z, Hu Y, Liang W, Ou C, He J, Liu L,et al. (2020). Clinical characteristics of coronavirus disease 2019 in China. N Engl J Med, 382:17081720. doi: 10.1056/NEJMoa2002032.

Hafiz M, Icksan AG, Harlivasari AD, Aulia R, Susanti F, Eldinia L (2020). Clinical, radiological features and outcome of COVID-19 patients in a secondary hospital in Jakarta, Indonesia. J Infect Dev Ctries, 14(7):750757. doi: 10.3855/jidc.12911.

Hu H, Ma F, Wei X, Fang Y (2020). Coronavirus fulminant myocarditis saved with glucocorticoid and human immunoglobulin. Eur Heart J: ehaa190. doi: 10.1093/eurheartj/ehaa190.

Hua J, Shaw R (2020). Corona virus (COVID-19) "infodemic" and emerging issues through a data lens: the case of China.Int J Environ Res Public Health, 17(7):2309. doi: 10.3390/ijerph17072309.

Huang G, Kovalic AJ, Graber CJ (2020). Prognostic value of leukocytosis and lymphopenia for coronavirus disease severity. Emerg Infect Dis, 26(8): 1839-1841. doi: 10.3201/eid2608.201160.

Itodo GE, Enitan SS, Oyekale AO, Agunsoye CJ, Asukwo UF, Enitan CB (2020). COVID-19 among healthcare workers : risk of exposure, impacts and biosafety measures - a review.IJHSE, 
6(4):534-548.

Jajodia A, Ebner L, Heidinger B, Chaturvedi A, Prosch $\mathrm{H}$ (2020). Imaging in corona virus disease 2019 (COVID-19) - a scoping review.Eur J Radiol Open, 7: 100237. doi: 10.1016/j.ejro.2020.100237.

Jin Y, Yang H, Ji W, Wu W, Chen S, Zhang W, Duan G (2020). Virology, epidemiology, pathogenesis, and control of COVID-19. Viruses, 12(4):372. doi: 10.3390/v12040372.

Karyono DR, Wicaksana AL (2020). Current prevalence, characteristics, and comorbidities of patients with COVID-19 in Indonesia. JCOEMPH, 3(2): 77-84. doi: 10.22146/jcoemph.57325 .

Kho J, Ioannou A, Abbeele KVD, Mandal AKJ, Missouris CG (2020). Pulmonary embolism in COVID-19: clinical characteristics and cardiac implications. Am J Emerg Med. doi: 10.1016/j.ajem.2020.07.054.

Liao J, Fan S, Chen J, Wu J, Xu S, Guo Y, Li $\mathrm{C}$, et al. (2020). Epidemiological and clinical characteristics of COVID-19 in adolescents and young adults.The Innovation, 1(1): 100001. doi: 10.1016/j.xinn.2020.04.001.

Lippi G, Mattiuzzi, C (2020). Hemoglobin value may be decreased in patients with severe coronavirus disease 2019. Hematol Transfus Cell Ther, 42(2): 116-117. doi: 10.1016/j.htct.2020.03.001.

Liu J, Liu Y, Xiang P, Pu L, Xiong H, Li C, Zhang M,et al. (2020). Neutrophil-tolymphocyte ratio predicts critical illness patients with 2019 coronavirus disease in the early stage.J Transl Med, 18(1): 206. doi: 10.1186/s12967020-02374-0.

Liu Y, Bi L, Chen Y, Wang Y, Fleming J, Yu $\mathrm{Y}, \mathrm{Gu} \mathrm{Y}$, et al. (2020). Active or latent tuberculosis increases susceptibility to COVID-19 and disease severity. MedRxiv preprint. doi: 10.1101/2020.03.10.20033795 .

Mccullough SA, Goyal P, Krishnan U, Choi JJ, Safford MM, Okin PM (2020) Electrocardiographic findings in coronavirus disease-19: insights on mortality and underlying myocardial processes. J Card Fail, 26(7): 626-632. doi: 10.1016/j.cardfail.2020.06.005.

Merino JL, Martinez-Cossiani M, Iniesta A, Escobar C, Rey JR, Castrejon-Castrejon S (2020). COVID-19 and QT interval prolongation: more than just drug toxicity? Europace, euaa145. doi: 10.1093/europace/euaa145.

Pinto BGG, Oliveira AER, Singh Y, Jimenez L, Goncalves ANA, Ogava RLT, et al. (2020). ACE2 expression is increased in the lungs of patients with comorbidities associated with severe COVID-19.J Infect Dis, 222(4): 556-563. doi: 10.1093/infdis/jiaa332.

Rodriguez-Morales AJ, Cardona-Ospina JA, Gutierrez-Ocampo E, Villamiraz-Pena R, Holguin-Rivera Y, Escalera-Antezana JP, Alvarado-Arnez LE, et al. (2020). Clinical, laboratory and imaging features of COVID-19: a systematic review and meta-analysis. Travel Med Infect Dis, 34: 101623. doi: 10.1016/j.tmaid.2020.101623.

Rosa SGV, Santos WC (2020). Clinical trials on drug repositioning for COVID-19 treatment.Rev Panam Salud Publica, 44:e40. doi: 10.26633/RPSP.2020.40.

Sarkodie BD, Osei-Poku K, Brakohiapa E (2020). Diagnosing COVID-19 from chest $\mathrm{x}$-ray in resource limited environment-case Report. Med Case Rep, 6(1): 135. doi: 10.36648/2471-8041.6.2.135.

Sia CH, Ngiam JN, Chew N, Beh DLL, Poh 
LK (2020). Educational case series of electrocardiographs during the COVID-19 pandemic and the implications for therapy.Singapore Med J, 61(8): 406-412. doi: 10.11622/smedj.2020087.

Singhal T (2020).A review of coronavirus disease-2019 (COVID-19). Indian $\mathrm{J}$ Pediatr, 87(4): 281-286. doi: 10.1007/s12098-020-03263-6.

Sultana J, Cutroneo PM, Crisafulli S, Puglisi G, Caramori G, Trifiro G (2020). Azithromycin in COVID-19 patients: pharmacological mechanism, clinical evidence and prescribing guidelines. Drug Saf. doi: 10.1007/s40264-02000976-7.

Violetis OA, Chasouraki AM, Giannou AM, Baraboutis IG (2020). COVID-19 infection and haematological involvement: a review of epidemiology, pathophysiology and prognosis of full blood count findings.SN Compr Clin Med. doi: 10.1007/s42399-020-00380-3.

World Health Organization (2020).WHO Coronavirus Disease (COVID-19) Dashboard. Available at: https://covid19.who.int/ (Accessed 3 September 2020).

Wong HYF, Lam HYS, Fong AHT, Leung ST, Chin TWY, Lo CSY, Lui MMS, et al. (2020). Frequency and distribution of chest radiographic findings in patients positive for COVID-19. Radiology, 296(2): E72-E78. doi: 10.1148/radiol.2020201160.
Wu R, Wang L, Kuo HCD, Shannar A, Peter R, Chou PJ, Li S, et al. (2020).An update on current therapeutic drugs treating COVID-19.Curr Pharmacol Rep. doi: 10.1007/s40495-020-00216-7.

Xu B, Xing Y, Peng J, Zheng Z, Tang W, Sun Y, Xu C,et al. (2020).Chest CT for detecting COVID-19: a systematic review and meta-analysis of diagnostic accuracy. Eur Radiol. doi: 10.21203/rs.3.rs-20481/v1.

Yavuz SS, Unal S (2020). Antiviral treatment of COVID-19. Turk J Med Sci, 50(3): 611-619. doi: 10.3906/sag-2004-145.

Zeng F, Huang Y, Guo Y, Yin M, Chen X, Xiao L, Deng G (2020). Association of inflammatory markers with the severity of COVID-19: A meta-analysis.Int J Infect Dis, 96: 467-474. doi: 10.1016/j.ijid.2020.05.055.

Zhao H, Lu X, Deng Y, Tang Y, Lu J (2020). COVID-19: asymptomatic carrier transmission is an underestimated problem.Epidemiol Infect, 148: e116. doi: 10.1017/So950268820001235.

Zheng J (2020). SARS-CoV-2: an emerging coronavirus that causes a global threat. Int J Biol Sci, 16(10):16781685. doi: 10.7150/ijbs.45053.

Zhu N, Zhang D, Wang W, Li X, Yang B, Song J, Zhao X,et al. (2020). A novel coronavirus from patients with pneumonia in China, 2019.N Engl J Med, 382(8): 727-733. doi: 10.1056/NEJMoa2001017. 